\title{
TECNOLOGIAS ASSISTIVAS NA ESCOLARIZAÇÃO DE ALUNOS COM DEFICIÊNCIA EM BELÉM-PA
}

ASSISTIVE TECHNOLOGIES IN SCHOOLING DISABLED STUDENTS IN BELÉM-PA

\section{TECNOLOGÍAS DE ASISTENCIA EN LA ESCOLARIZACIÓN DE ESTUDIANTES CON DISCAPACIDADES EN BELÉM-PA}

\author{
Angela Costa de Sousa ${ }^{1}$ \\ Amélia Maria Araújo Mesquita ${ }^{2}$
}

RESUMO:

O presente artigo se propõe a apresentar dados preliminares de uma pesquisa que visa analisar de que forma a Rede Municipal de Ensino de Belém tem garantido equipar as Salas de Recursos Multifuncionais (SRM) com Tecnologias Assistivas, considerando que essas são fundamentais no processo de escolarização de alunos com deficiência. Assim, neste trabalho nos propomos a apresentar as ações realizadas pela Secretaria Municipal de Educação de Belém (SEMEC) para a oferta de Tecnologias Assistivas nas SRM, conforme prevê o Plano Municipal de Educação em vigor neste município. O estudo foi realizado com base em uma abordagem qualitativa, por meio da pesquisa documental. Como resultado destaca-se, a partir dos documentos municipais, que a rede faz o levantamento quadrianual das necessidades de acessibilidade das escolas, contudo, ainda há a necessidade de aproximar os recursos de Tecnologias Assistivas ao perfil do público que atende.

PALAVRAS-CHAVE:

Submetido em: 15/01/2020 - Aceito em: 19/04/2020 - Publicado em: 29/04/2020

${ }^{1}$ Graduada em Pedagogia pela Universidade Federal do Pará, Especialista em Docência do Ensino Superior pela Escola Superior da Amazônia (ESAMAZ). Tem experiência na área de Educação, pois atuou na Educação Infantil no ano de 2009. Desde 2013 é servidora pública efetiva da Rede Municipal de Ensino de Belém-PA atuando como professora do Ensino Fundamental I / Instituição/Afiliação: Universidade Federal do Pará - UFPA.

${ }^{2}$ Graduada em Pedagogia pela Universidade Federal do Pará, Mestre em Educação na Linha de Currículo e Formação de Professores e Doutora em Educação na Linha de Educação: Currículo, Epistemologia e História pelo Programa de Pós-Graduação em Educação do Instituto de Ciências da Educação da Universidade Federal do Pará. É Professora Adjunto III do Núcleo de Estudos Transdisciplinares em Educação Básica (NEB) e atua no Programa de Pós-Graduação em Currículo e Gestão da Escola Básica (PPEB/NEB/UFPA) É vice-líder do Grupo de Estudos e Pesquisa sobre Currículo e Formação de Professores na Perspectiva da Inclusão INCLUDERE, e pesquisadora do Grupo de Estudos e Pesquisa sobre Infâncias e Educação - INFANCE. Tem experiência na área de Educação, atuando principalmente nos seguintes temas: currículo, práticas curriculares, inclusão de alunos com deficiência na escola básica e didática / Instituição/Afiliação: Universidade Federal do Pará - UFPA. 


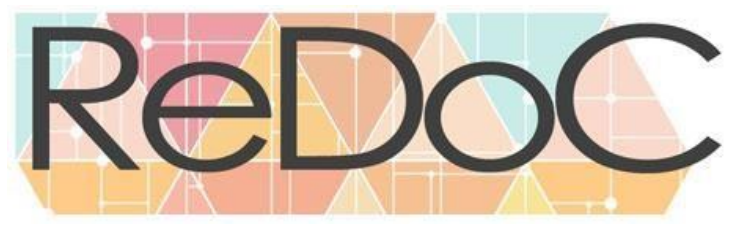

Revista Docência e Cibercultura

Tecnologias Assistivas. Inclusão Escolar. Educação Especial.

\section{ABSTRACT}

This article aims to present preliminary data from a research that aims to analyze how the Belém Municipal Teaching Network has ensured to equip the Multifunctional Resource Rooms (SRM) with Assistive Technologies, considering that these are fundamental in the schooling process. students with disabilities. Thus, in this paper we propose to present the actions carried out by the Belém Municipal Secretariat of Education (SEMEC) for the provision of Assistive Technologies in SRM, as provided for in the Municipal Education Plan in force in this municipality. The study was conducted in a qualitative approach through documentary research. As a result, the municipal documents show that the network makes a four-year survey of the accessibility needs of schools. However, there is still a need to bring the resources of Assistive Technologies closer to the profile of the public that serves them.

\section{KEYWORDS:}

Assistive Technologies. School Inclusion. Special Education.

\section{RESUMEN}

Este artículo tiene como objetivo presentar datos preliminares de una investigación que tiene como objetivo analizar cómo la Red de Enseñanza Municipal de Belém se ha asegurado de equipar las Salas de Recursos Multifuncionales (SRM) con Tecnologías de Asistencia, considerando que son fundamentales en el proceso de escolarización. estudiantes con discapacidad Por lo tanto, en este documento proponemos presentar las acciones llevadas a cabo por la Secretaría Municipal de Educación de Belém (SEMEC) para la provisión de Tecnologías de Asistencia en SRM, según lo previsto en el Plan de Educación Municipal vigente en este municipio. El estudio se realizó en un enfoque cualitativo a través de la investigación documental. Como resultado, los documentos municipales muestran que la red realiza una encuesta de cuatro años sobre las necesidades de accesibilidad de las escuelas, sin embargo, aún existe la necesidad de acercar los recursos de las Tecnologías de Asistencia al perfil del público que los atiende.

\section{PALABRAS CLAVE:}

Tecnologías de Asistencia. Inclusión Escolar. Educación Especial.

\section{INTRODUÇÃO}

Este artigo tem por finalidade apresentar os resultados parciais de uma pesquisa em andamento no curso de mestrado no Programa de Pós-Graduação em Currículo e Gestão da Escola Básica (PPEB/NEB), da Universidade Federal do Pará. A pesquisa se propõe analisar as ações realizadas pela Secretaria Municipal de Educação de Belém (SEMEC), no período de 2014 a 2018, para a oferta de Tecnologias Assistivas nas Salas de Recursos Multifuncionais (SRM) como forma de garantir a inclusão escolar para alunos com deficiência em sua rede municipal de ensino, conforme prevê o Plano Municipal de Educação em vigor neste município desde 2015, com vigência até 2025. 


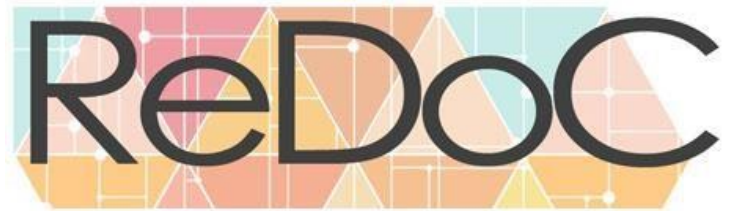

Revista Docência e Cibercultura

A pesquisa se justifica pela possibilidade de analisar a oferta de recursos de Tecnologias Assistivas pelas redes de ensino para qualificar a escolarização de alunos com deficiência na escola regular. As Tecnologias Assistivas estão emergindo como ferramentas essenciais que potencializam o processo de escolarização de alunos com deficiência na escola regular. Atualmente, existem em vigor em nosso país, diversas políticas públicas educacionais que asseguram a oferta de recursos de Tecnologias Assistivas como forma de garantir a inclusão escolar na rede regular de ensino. Diante desse contexto, é necessário conhecer o que o município de Belém, via Secretaria Municipal de Educação, tem oferecido às escolas públicas em termos de recursos de Tecnologias Assistivas como suporte para a efetivação da inclusão escolar em sua rede pública de ensino.

Os dados coletados até o momento ainda não nos permitem responder o problema de pesquisa investigado no curso de mestrado, mas já nos fornecem elementos preliminares na problematização das condições para escolarização de pessoas com deficiência na rede regular de ensino, diante de significativos avanços nas propostas e políticas de inclusão escolar em todo o país.

Este texto está estruturado em subtópicos que objetivam discutir inicialmente a inclusão educacional na rede regular de ensino, bem como as políticas de serviços de apoio especializados. Em seguida, abordaremos a discussão sobre Tecnologias Assistivas para, posteriormente, adentrarmos nos procedimentos e resultados parciais da pesquisa documental realizada na rede municipal de ensino de Belém-PA.

Inclusão educacional na rede regular de ensino e políticas de serviços de apoio especializados 


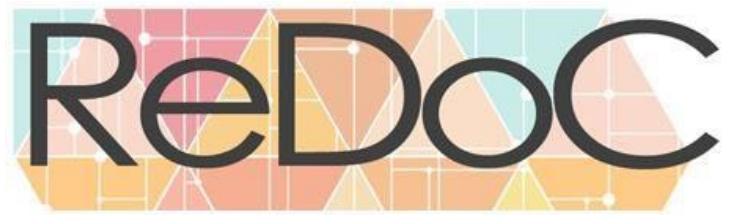

Revista Docência e Cibercultura

O discurso da inclusão escolar surgiu na década 1990 com os avanços decorrentes de dois grandes encontros internacionais, considerados marcos mundiais na difusão da filosofia da Educação Inclusiva e que embasaram as teorias e práticas de Educação Inclusiva em vários países, inclusive o Brasil, quais sejam: a Conferência Mundial de Educação para Todos, realizada em Jomtien, na Tailândia, em 1990; e a Conferência Mundial de Educação Especial, realizada na Espanha, em 1994, pela UNESCO, da qual resultou a Declaração de Salamanca (BEYER, 2009).

Antunes (2008) reitera que, após a Conferência Mundial de Educação para Todos e a Declaração de Salamanca, ocorreram mudanças expressivas de mentalidade no campo dos direitos sociais. Tais mudanças marcaram o início de uma caminhada rumo a implementação da Educação Inclusiva.

\begin{abstract}
A inclusão se apoia na aceitação das diferenças individuais como atributo, jamais como um obstáculo no direito de participar. Parece ter chegado a hora de descobrir que é essencial valorizar o que a espécie humana possui de mais extraordinário sua formidável diversidade (ANTUNES, 2008, p.18).
\end{abstract}

A partir das ideias de inclusão ${ }^{3}$ veiculadas pelos documentos internacionais resultantes das conferências mundiais, ocorre o início da formulação e implementação de políticas públicas educacionais orientadas pelo paradigma da inclusão escolar em muitos países, dentre os quais, o Brasil.

No Brasil, atualmente existe um conjunto de leis, decretos, resoluções e portarias (conforme ilustra o quadro 1) que orientam a consolidação da Educação Especial na perspectiva de Educação Inclusiva, criando programas, projetos e ações governamentais para a

\footnotetext{
${ }^{3}$ Vale ressaltar que a proposta de Educação Inclusiva nestes documentos não se restringe apenas ao público de pessoas com deficiência. Os documentos abrangem outros grupos de sujeitos que sofrem exclusões sociais em diversas esferas de suas vidas. No entanto, neste artigo, estamos nos referindo apenas às políticas públicas de apoio a escolarização de pessoas com deficiências.
} 


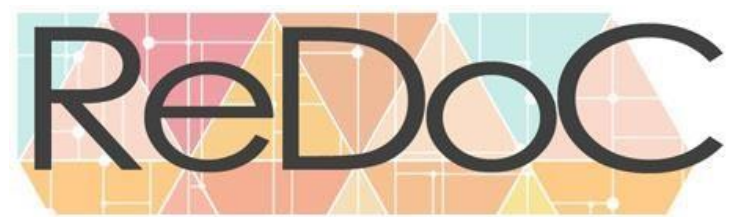

Revista Docência e Cibercultura

institucionalização de serviços de apoio à inclusão escolar na rede regular de ensino. Glat e Blanco (2007, p.23) sinalizam que a "Educação Inclusiva é atualmente a política educacional oficial do país, amparada pela legislação em vigor, e convertida em diretrizes para a Educação Básica dos sistemas Federal, estaduais e municipais”. Destacamos a pertinência dessa afirmativa ao atual contexto se tomarmos como referência a implementação das políticas de inclusão no cenário brasileiro.

Quadro 1: Lista de documentos orientadores de ações na perspectiva da Educação Inclusiva

\begin{tabular}{|c|c|}
\hline Documentos /ano & Descritor \\
\hline Resolução n' 2 / 2001 & $\begin{array}{l}\text { Institui as Diretrizes Nacionais para a Educação Especial na } \\
\text { Educação Básica }\end{array}$ \\
\hline 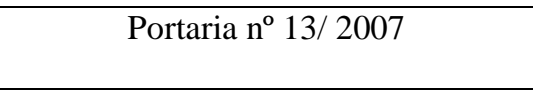 & $\begin{array}{l}\text { Dispõe sobre a criação do "Programa de Implantação de Salas de } \\
\text { Recursos Multifuncionais" }\end{array}$ \\
\hline $\begin{array}{c}\text { Política Nacional de Educação } \\
\text { Especial na Perspectiva da Educação } \\
\text { Inclusiva / } 2008\end{array}$ & $\begin{array}{l}\text { Fixa a Política Nacional de Educação Especial na Perspectiva da } \\
\text { Educação Inclusiva }\end{array}$ \\
\hline Resolução nº 4 / 2009 & $\begin{array}{l}\text { Institui as Diretrizes Operacionais para o Atendimento } \\
\text { Educacional Especializado na Educação Básica, na modalidade } \\
\text { Educação Especial. }\end{array}$ \\
\hline Decreto $^{\circ}{ }^{\circ} 7.611 / 2011$ & $\begin{array}{l}\text { Dispõe sobre a educação especial, o atendimento educacional } \\
\text { especializado e dá outras providências. }\end{array}$ \\
\hline Lei $n^{\circ} 13.146 / 2015$ & $\begin{array}{l}\text { Institui a Lei Brasileira de Inclusão da Pessoa com Deficiência } \\
\text { (Estatuto da Pessoa com Deficiência). }\end{array}$ \\
\hline
\end{tabular}

Fonte: Elaborado pelas autoras com base em pesquisa documental realizada em sítios eletrônicos no ano de 2019.

Ao longo dessas duas décadas do século XXI, ocorreram significativos avanços na implementação de políticas para a inclusão escolar de alunos público alvo da educação especial que culminaram com a implementação, por exemplo, do Atendimento Educacional Especializado (AEE); das Salas de Recursos Multifuncionais (SRMs); e do Programa Escola Acessível. Este último objetiva promover a acessibilidade arquitetônica dos prédios escolares. Vale ressaltar que tais avanços na política de inclusão foram estabelecidos desde a Lei de Diretrizes e Bases da Educação (Lei 9.394/1996), quando a Educação Especial se transforma em modalidade de educação escolar a ser oferecida preferencialmente na rede regular de ensino desde a educação infantil, estendendo-se ao longo da vida, mediante 


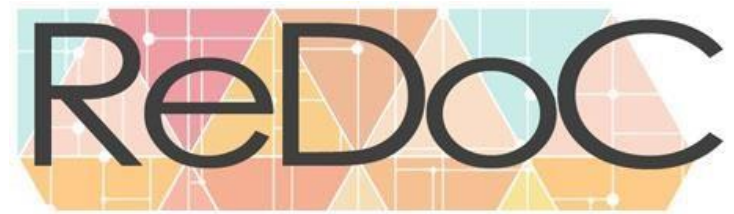

Revista Docência e Cibercultura

serviços de apoio especializados destinados a grupos específicos de alunos: educandos com deficiência, transtornos globais do desenvolvimento e altas habilidades ou superdotação ${ }^{4}$. Neste panorama, os sistemas de ensino, aos poucos, estruturam-se para esse atendimento.

Em 2001, a Resolução no 2, do CEB/CNE/ 2001, instituiu as Diretrizes Nacionais para a Educação Especial na Educação Básica. Neste documento são definidas as competências e responsabilidades dos sistemas de ensino, escolas e profissionais da educação, diante da escolarização de pessoas com deficiência na rede regular de ensino, conforme indicam os excertos da lei apresentados a seguir:

\begin{abstract}
Art $2^{\circ}$ Os sistemas de ensino devem matricular todos os alunos, cabendo às escolas organizar-se para o atendimento aos educandos, assegurando as condições necessárias para uma educação de qualidade para todos.

$[\ldots]$

Parágrafo único. Os sistemas de ensino devem constituir e fazer funcionar um setor responsável pela educação especial, dotado de recursos humanos, materiais e financeiros que viabilizem e dêem sustentação ao processo de construção da educação inclusiva.

[...]

Art. 12. Os sistemas de ensino, nos termos da Lei 10.098/2000 e da Lei $10.172 / 2001$, devem assegurar a acessibilidade aos alunos que apresentem necessidades educacionais especiais, mediante a eliminação de barreiras arquitetônicas urbanísticas, na edificação - incluindo instalações, equipamentos e mobiliário - e nos transportes escolares, bem como de barreiras nas comunicações, provendo as escolas dos recursos humanos e materiais necessários (BRASIL, 2001, p.03).
\end{abstract}

Ainda a respeitos das políticas de Educação Inclusiva, a Portaria $n^{\circ} 13 / 2007$ criou o Programa de Implantação de Salas de Recursos Multifuncionais nas escolas públicas com o objetivo de apoiar os sistemas públicos de ensino na organização e oferta do atendimento educacional especializado, contribuindo para o fortalecimento da Educação Inclusiva. Neste mesmo documento, o atendimento educacional especializado constitui-se em estratégia para que estados e municípios pudessem prover uma educação de qualidade para todos os alunos, gerando condições de acessibilidade para garanta da participação nos espaços comuns de

\footnotetext{
${ }^{4}$ Esse grupo foi delimitado com a implementação da Política Nacional de Educação Especial na Perspectiva da Educação Inclusiva de 2008.
} 


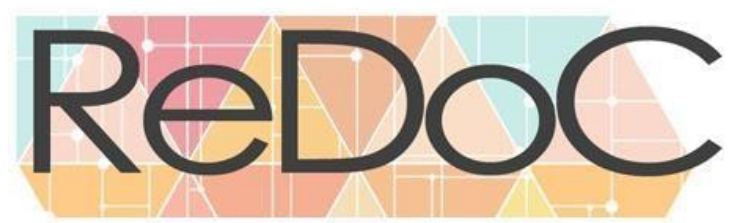

Revista Docência e Cibercultura

ensino e aprendizagem. No parágrafo único dessa Portaria define-se que a "sala de recursos é um espaço organizado com equipamentos de informática, ajudas técnicas, materiais pedagógicos e mobiliários adaptados, para atendimento às necessidades educacionais especiais dos alunos" (BRASIL, 2007, p.01).

Ampliando o repertório de serviços para a inclusão escolar, a Política Nacional de Educação Especial na Perspectiva da Educação Inclusiva, criada em 2008, reafirma a educação especial como modalidade de ensino que perpassa todos os níveis, etapas e modalidades da educação, tendo como objetivo assegurar a inclusão na escola. De acordo com a Política:

\begin{abstract}
O atendimento educacional especializado tem como função identificar, elaborar e organizar recursos pedagógicos e de acessibilidade que eliminem as barreiras para a plena participação dos estudantes, considerando suas necessidades específicas. As atividades desenvolvidas no atendimento educacional especializado diferenciam-se daquelas realizadas na sala de aula comum, não sendo substitutivas à escolarização. Esse atendimento complementa e/ou suplementa a formação dos estudantes com vistas à autonomia e independência na escola e fora dela [...] Dentre as atividades de atendimento educacional especializado são disponibilizados programas de enriquecimento curricular, o ensino de linguagens e códigos específicos de comunicação e sinalização e tecnologia assistiva (BRASIL, 2008, p.11).
\end{abstract}

Quixaba (2015) aponta que a Política de Educação Especial na Perspectiva da Educação Inclusiva constitui um documento de bastante relevância no contexto da Educação Inclusiva, mas apresenta caráter contraditório em relação a sua implementação, sendo necessário instituir outros dispositivos fundamentais, a exemplo do Decreto ${ }^{\circ}$ 6.571/2008 (atualmente revogado pelo Decreto $n^{\circ}$ 7.611/2011) e a Resolução $n^{\circ}$ 4/2009 do CEB/CNE, para dar suporte a sua implementação. Esta última, representa uma política de grande relevância para a escolarização de pessoas com deficiência: a Resolução $n^{\circ} 4$, de 2009 , define as Diretrizes Operacionais para o Atendimento Educacional Especializado na Educação Básica (AEE), modalidade Educação Especial, estabelecendo que o AEE deve ocorrer, preferencialmente, nas salas de recursos das escolas regulares da rede pública de ensino ou, em centros de Atendimento Educacional Especializado da rede pública ou ainda, em 


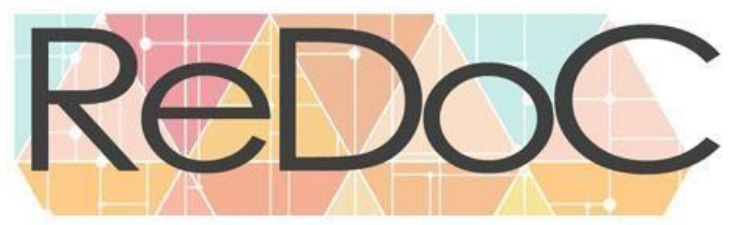

Revista Docência e Cibercultura

instituições comunitárias, confessionais ou filantrópicas sem fins lucrativos, como suporte aos alunos com necessidades pedagógicas diferenciadas na superação das barreiras e limitações presentes em seu processo de escolarização. Outro ponto importante desta política diz respeito ao financiamento público das matrículas no AEE.

\begin{abstract}
Art. $8^{\circ}$ Serão contabilizados duplamente, no âmbito do FUNDEB, os alunos matriculados em classe comum de ensino regular público que tiverem matrícula concomitante no AEE.

Parágrafo único. O financiamento da matrícula no AEE é condicionado à matrícula no ensino regular da rede pública, conforme registro no Censo Escolar/MEC/INEP do ano anterior, sendo contemplada:

a) matrícula em classe comum e em sala de recursos multifuncionais da mesma escola pública; b) matrícula em classe comum e em sala de recursos multifuncionais de outra escola pública; c) matrícula em classe comum e em centro de Atendimento Educacional Especializado de instituição de Educação Especial pública; d) matrícula em classe comum e em centro de Atendimento Educacional Especializado de instituições de Educação Especial comunitárias, confessionais ou filantrópicas sem fins lucrativos (BRASIL, 2009, p. 02).
\end{abstract}

A Lei $\mathrm{n}^{\circ}$ 13.146, de 6 de julho de 2015, instituiu a Lei Brasileira de Inclusão da Pessoa com Deficiência (Estatuto da Pessoa com Deficiência). Nesta lei a educação constitui um direito da pessoa com deficiência, a ser assegurado pelo sistema educacional inclusivo em todos os níveis de aprendizado ao longo de toda a vida. Os sistemas educacionais devem ser aprimorados visando garantir condições de acesso, permanência, participação e aprendizagem, por meio da oferta de serviços e de recursos de acessibilidade que eliminem as barreiras e promovam a inclusão plena.

Diante desse leque, cabe ressaltar que as políticas de inclusão para as pessoas com deficiência expandiram-se com mais intensidade na primeira década do século XXI. Esta expansão promoveu ampliação na oferta de serviços e recursos para o atendimento dos alunos identificados como público-alvo da educação especial na rede regular de ensino. No entanto, vale enfatizar que essa ampliação na oferta dos serviços de apoio à inclusão escolar não se efetivou de forma linear e generalizada, nem com a mesma intensidade por todos os estados e municípios brasileiros. Em função de tais distinções, em muitas regiões brasileiras 


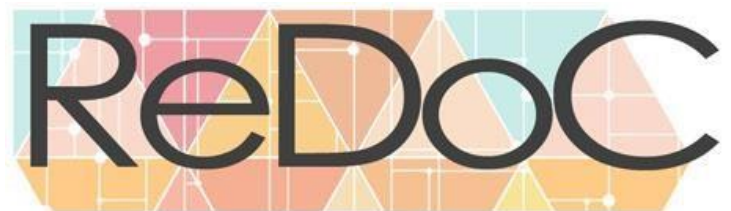

Revista Docência e Cibercultura

"tem sido constatado frequentes carências na oferta de serviços impossibilitando oportunidades educacionais" (QUIXABA, 2015, p.39). Com isso, o acesso aos recursos principalmente aqueles recursos de Tecnologias Assistivas mais avançadas - não se concretiza de forma "equitativa por todas as pessoas que necessitam ser beneficiadas por seu uso" (LÍBERA; SILVA, 2019, p.134). Assim, o problema da exclusão educacional não reside na ausência de amparo legal, mas, na ausência de condições objetivas para que as políticas sejam efetivadas. A despeito dos obstáculos e limitações, ressalta-se que "as políticas educacionais direcionadas aos alunos com deficiência alcançaram nas últimas décadas visibilidade sem precedentes" (QUIXABA, 2015, p.79).

Portanto, as políticas públicas são de fundamental importância para a construção de um sistema educacional inclusivo, tendo em vista que por meio delas são definidas e implementadas diretrizes, programas e ações com vistas ao encaminhamento da demanda para a qual foram criados. Nesta direção convém destacar os avanços ocorridos no campo das políticas públicas de inclusão escolar - ainda que minimamente, sob o ponto de vista legal - buscando-se designar serviços de apoio à inclusão escolar, como forma de garantir aos alunos acesso ao conhecimento no espaço escolar. A partir deste cenário, cabe repensar o papel da escola diante dessa perspectiva de escolarizar. Esta temática será abordada na próxima subseção.

\section{Tecnologias Assistivas: recursos que colaboram para com o processo de escolarização dos alunos público-alvo da educação especial}

Tecnologia Assistiva (TA) é uma expressão relativamente nova. Surgiu oficialmente na legislação estadunidense. No Brasil, o conceito de TA foi instituído em 16 de novembro 2006 pela Portaria $n^{\circ}$ 142, do Comitê de Ajuda Técnicas (CAT), na perspectiva de aperfeiçoar, conferir transparência e legitimidade ao desenvolvimento da TA no Brasil. 


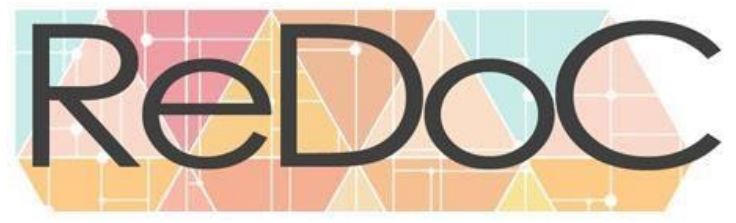

Revista Docência e Cibercultura

A Tecnologia Assistiva "é uma área do conhecimento que desenvolve serviços, recursos e estratégias que auxiliam na resolução de dificuldades funcionais das pessoas com deficiência para a realização de tarefas no cotidiano" (CAT, 2007, p.05). Esta definição é citada na grande maioria dos artigos, dissertações, teses e livros consultados sobre essa temática (BERSCH, 2009; GALVÃO FILHO, 2009; CORRÊA; RODRIGUES, 2016).

Para Bersch (2007) a Tecnologia Assistiva:

é uma expressão utilizada para identificar todo o arsenal de recursos e serviços que contribuem para proporcionar ou ampliar habilidades funcionais de pessoas com deficiência e, consequentemente, promover vida independente e inclusão" (BERSCH, 2007, p.31).

Ainda a respeito do conceito de Tecnologia Assistiva, a Lei ${ }^{\circ}$ 13.146/ 2015, chamada de Lei Brasileira de Inclusão, ou Estatuto da Pessoa com Deficiência, traz um conceito mais amplo, definindo-a como:

[...] produtos, equipamentos, dispositivos, recursos, metodologias, estratégias, práticas e serviços que objetivem promover a funcionalidade, relacionada à atividade e à participação da pessoa com deficiência ou com mobilidade reduzida, visando à sua autonomia, independência, qualidade de vida e inclusão social. (BRASIL, 2015a).

A finalidade da TA é promover funcionalidade, autonomia, independência, qualidade de vida e inclusão social das pessoas com deficiência, pessoas com mobilidade reduzida e/ou pessoas idosas. Em virtude desta finalidade, Garcia et al. (2017) consideram que:

[...] a TA deve ser entendida como um direito humano e social, uma vez que os distintos produtos e serviços de apoio podem ser considerados como verdadeiras complementações e extensões da corporeidade e do próprio ser das pessoas que deles se utilizam e/ou precisam se utilizar, assegurando possibilidades efetivas de comunicação, expressão, movimento e consecução de atividades da vida diária, enfim, de realização plena como pessoas humanas e sujeitos de direitos participantes da vida social (GARCIA et al., 2017, p.12/13).

Atualmente, impulsionada pelo novo paradigma da inclusão social que defende a participação de pessoas com deficiência nos diversos ambientes da sociedade, a TA representa uma área em ascensão e vem se tornando cada vez mais presente no campo 


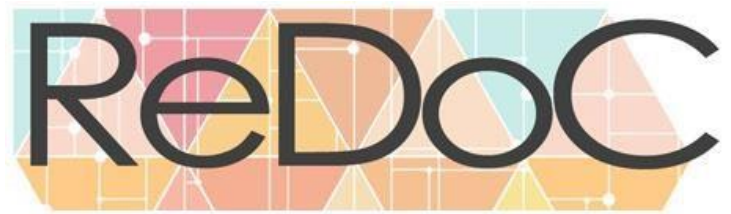

Revista Docência e Cibercultura

educacional, nos processos de escolarização de alunos com deficiências. O seu uso é de fundamental importância para a inserção e permanência destes na escola regular, ampliando as possibilidades de comunicação e interação entre professor-aluno e, entre aluno-aluno.

\begin{abstract}
O acesso a tecnologia assistiva é, na verdade, um direito do aluno com deficiência, a fim de que o mesmo possa exercer direitos dos mais fundamentais, que, com frequência, na ausência dessas tecnologias não poderiam ser exercidos como, por exemplo, o direito à comunicação, a interação, expressão autônoma do pensamento, ao aprendizado, dentre outros (GALVÃO FILHO; MIRANDA, 2011, p 08).
\end{abstract}

Neste sentido, o uso de variadas estratégias de ensino, sobretudo aquelas que envolvam a Tecnologia Assistiva, pode se tornar o diferencial nas condições de permanência e de sucesso escolar de estudantes, com ou sem deficiência, no processo de escolarização, pois sua finalidade reside em auxiliar o aluno a realizar as tarefas escolares, proporcionando-lhes autonomia na execução destas, visando aumentar a participação do mesmo nas atividades relativas a seu processo de escolarização (CORRÊA; RODRIGUES, 2016).

De modo geral, os recursos de Tecnologia Assistiva são organizados ou classificados de acordo com objetivos funcionais a que se destinam: Auxílios para a vida diária; Comunicação aumentativa e alternativa; Recursos de acessibilidade ao computador; Sistema de controle de ambiente; Projetos arquitetônicos de acessibilidade; Órteses e próteses; Adequação postural; Auxílios de mobilidade; Auxílios para cegos ou com visão subnormal; Auxílios para surdos ou com déficit auditivo; e Adaptações de veículos.

Os recursos de TA disponíveis na escola podem ser: recursos de acessibilidade computacional - facilitam o processamento de informações e conteúdos escolares, funcionando como um facilitador na aprendizagem; os recursos de comunicação alternativa - utilizados para estudantes que apresentam comprometimentos severos de fala; auxílios de mobilidade; adequação postural; adaptações de recursos escolares a serem utilizados com o aluno. As adaptações nos materiais escolares proporcionam ao aluno, público-alvo da Educação Especial, condições de manuseio de objetos escolares favoráveis a sua

\begin{tabular}{|l|l|}
\hline v. 4 & n. 1
\end{tabular}




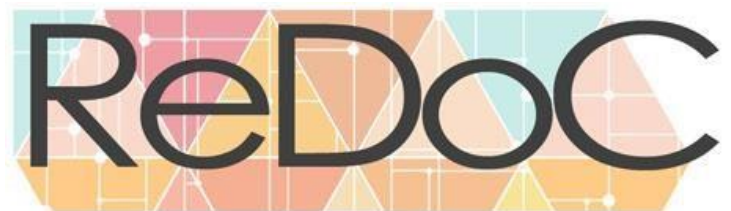

Revista Docência e Cibercultura

necessidade, facilitando assim melhores condições de ensino-aprendizagem e, permitindo ao aluno o desempenho das atividades acadêmicas com o maior grau de funcionalidade possível (FACHINETTI; CARNEIRO, 2017).

Ainda que as salas de recursos multifuncionais se constituam em "espaços privilegiados para que o estudante com deficiência aprenda a usar a Tecnologia Assistiva como ferramenta para o desenvolvimento da aprendizagem e da autonomia" (CORRÊA; RODRIGUES, 2016, p.07), também é de fundamental importância enfatizarmos que os recursos de Tecnologias Assistivas sejam utilizados pelos alunos público-alvo da Educação Especial nos demais espaços escolares. Neste sentido, o acesso aos serviços e recursos pedagógicos de acessibilidade nas escolas públicas favorecem um maior desenvolvimento acadêmico e social do estudante, uma vez que possibilitam que estes estudantes "participem e atuem positivamente nas várias atividades propostas no currículo comum” (BERSCH, 2009, p.22).

Portanto, como observado no desenvolvimento deste trabalho, a Tecnologia Assistiva é uma área em expansão, que tem adentrado o campo da educação por meio de recursos, produtos e serviços que buscam qualificar o processo de escolarização dos alunos que se constituem o público-alvo da educação especial na escola regular, tornando-se um direito destes e sua finalidade consiste em promover autonomia e independência na realização de tarefas no ambiente escolar e também fora dele (GALVÃo FILHO, 2009). Por esta razão, a oferta de Tecnologias Assistivas nas escolas públicas regulares é de fundamental importância para a inclusão educacional, pois o acesso do aluno aos recursos de Tecnologias Assistivas gera "condições de permanência e de sucesso na escolarização de estudantes com ou sem deficiência" (CORRÊA; RODRIGUES, 2016, p. 11).

\section{METODOLOGIA}




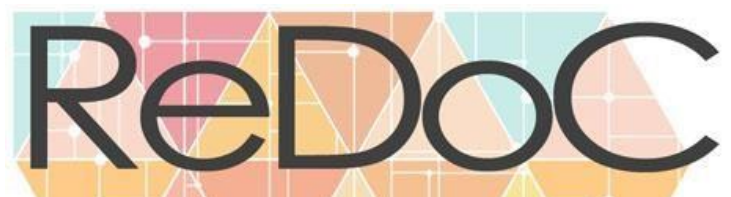

Revista Docência e Cibercultura

A pesquisa foi desenvolvida sob as bases de uma abordagem qualitativa, pautando-se na consideração da Educação Inclusiva como uma questão complexa, que envolve a ação de diferentes agentes e é resultado de embates no campo econômico, político, social e cultural, constituindo-se, portanto, um fenômeno dinâmico.

A pesquisa documental foi realizada nos meses de abril e maio de 2019, no banco de dados do Instituto Nacional de Estudos e Pesquisas Educacionais Anísio Teixeira - INEP, para obtenção do Censo Escolar, e em sítios eletrônicos do município de Belém, para o levantamento de documentos municipais desta cidade, que ofereçam subsídios para a implementação da Educação Especial, na perspectiva inclusiva, na rede municipal de ensino de Belém. Nessa busca foram encontrados seis documentos, a saber: Resolução $n^{\circ}$ 012/2007, que fixa as diretrizes e normas para o Atendimento Educacional Especializado no Sistema Municipal de Ensino de Belém; Plano Municipal de Educação de Belém (PME: 2015-2025); Projeto de Lei de Diretrizes Orçamentárias (PLDO 2016); Plano Plurianual do município de Belém, de 2017, elaborado para o quadriênio 2018-2021 e, dois documentos utilizados pela Secretaria Municipal de Educação de Belém (SEMEC) para o levantamento das necessidades de acessibilidade das escolas da rede. Além destes, foi usado também o Anuário Estatístico do município de Belém (2019) e o Censo Escolar dos últimos cinco anos.

Após a etapa de identificação e seleção desses documentos, foi realizada a leitura dos mesmos com a finalidade de se apropriar a respeito das propostas neles contidas, em termos de políticas, programas, e ações para a implementação da Educação Especial na perspectiva inclusiva, na rede municipal de ensino de Belém, bem como identificar de que forma o município de Belém, via Secretaria Municipal de Educação (SEMEC) está estruturando o serviço de apoio educacional especializado e a adoção de materiais didáticos e recursos pedagógicos em sua rede de ensino, destacando-se nesse processo as Tecnologias Assistivas.

\section{RESULTADOS}




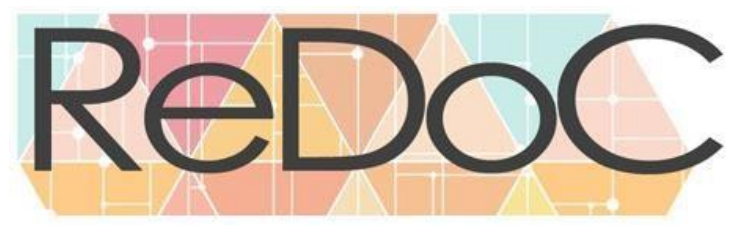

Revista Docência e Cibercultura

Na rede municipal de ensino de Belém, a Educação Especial desde o final da década de 1990, a partir do projeto Escola Cabana $^{5}$, tem sido pensada já na perspectiva de Educação Inclusiva. Desde então têm surgido, no município de Belém, ações voltadas à consolidação desta perspectiva de educação. Seguindo orientações das políticas educacionais nacionais e internacionais, o município elaborou seus próprios documentos norteadores das ações educacionais em sua rede de ensino. Em todos esses documentos, as tecnologias despontam como elemento essencial na escolarização de pessoas com deficiência.

Um desses documentos consiste na Resolução ${ }^{\circ}$. 12/2007, que fixou as Diretrizes e Normas Educacionais e Pedagógicas para o Atendimento dos educandos com necessidades especiais no Sistema Municipal de Ensino de Belém. Esta Resolução sinaliza a consolidação de um sistema municipal de educação fundamentado em uma perspectiva de Educação Inclusiva, assegurando a oportunidade de acesso, permanência e prosseguimento nos estudos, mediante ações que deverão prover:

\footnotetext{
I - redimensionamento do quadro de profissionais para a garantia do atendimento inclusivo;

II - formação continuada e permanente dos recursos humanos que atuam na docência, gestão e demais áreas do processo educativo;

III- adoção de medidas de acessibilidade à informação, à comunicação e à mobilidade, através da aquisição de recursos, mobiliários e equipamentos adaptados;

IV- construção e manutenção de uma rede de apoio para desenvolvimento de práticas colaborativas interinstitucionais que forneçam a oferta de serviços nas áreas da saúde, assistência social, jurídica, trabalho, esporte e lazer e de atendimentos educacionais especializados [...] (BELÉM, 2007, p.02).
}

\footnotetext{
${ }^{5}$ A proposta da Escola Cabana foi um projeto de governo do Partido dos Trabalhadores (PT), implementado em Belém do Pará, no período de 1997 a 2004, o qual traz em seu bojo o desenvolvimento de um trabalho coletivo de democratização do ensino, via movimento de reorientação curricular, expressando uma concepção política de educação, sintonizada com o projeto de emancipação das classes populares. Pautado nos princípios de Inclusão Social e Cidadania, o projeto Escola Cabana define quatro diretrizes básicas: Acesso e Permanência com Sucesso, Qualidade Social da Educação, Gestão Democrática do Sistema Municipal de Educação e Valorização Profissional dos Educadores da rede Municipal de Educação (FERREIRA, 2005, p 69).
} 


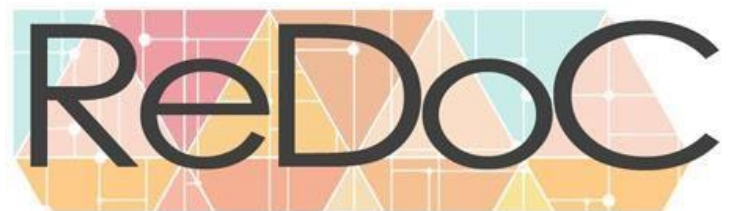

\section{Revista Docência e Cibercultura}

Nesta mesma Resolução elucida-se que o Atendimento Educacional Especializado tem a finalidade de remover as barreiras de aprendizagem, e para isso, será disponibilizado um conjunto de procedimentos específicos para a apropriação e produção do conhecimento pelos alunos. Outro aspecto destacado neste documento refere-se a ênfase atribuída aos recursos pedagógicos utilizados no Atendimento Educacional Especializado na rede pública, com destaque às Tecnologias Assistivas usadas para o "enriquecimento e aprofundamento do repertório de conhecimento do aluno" (BELÉM, 2007, p.03).

Ainda sobre os documentos municipais em vigor, na condução da política municipal de educação, foi aprovado o Plano Municipal de Educação de Belém (PME 2015-2025) através da Lei $n^{\circ}$ 9.129/2015, com vigência de dez anos. Neste Plano, são estabelecidas as diretrizes, as metas e as estratégias para a educação no município de Belém. São também propostas ações que visam promover: a melhoria da qualidade da educação com a ampliação dos investimentos públicos na educação, assegurando a qualidade e equidade no atendimento às necessidades de expansão; a valorização dos trabalhadores da educação; e o desenvolvimento da política de Educação Inclusiva, intensificando esforços para implementar e consolidar políticas educacionais e a elevação da qualidade do ensino escolar. Em relação a Educação Especial, assim como no Plano Nacional de Educação - PNE 20142024, a meta 4 do Plano Municipal prevê a universalização do acesso à Educação Básica e ao Atendimento Educacional Especializado (AEE) para alunos público-alvo da Educação Especial, na faixa etária de quatro a dezessete anos, matriculados em escolas públicas da rede regular de ensino. Para tanto, estabeleceu-se um conjunto de 23 estratégias a serem implementadas durante a vigência deste Plano, as quais transitam pela ampliação da oferta de vagas na rede de ensino; realização de parcerias; investimento na formação de professores; criação de centros construídos por equipes multiprofissionais; oferta de recursos tecnológicos e materiais didáticos pedagógicos para equipar as salas de recursos multifuncionais; dentre outras estratégias (BELÉM, 2015). Dentre estas estratégias, destacamos aquelas que estão relacionadas ao nosso objeto de estudo, quais sejam: 


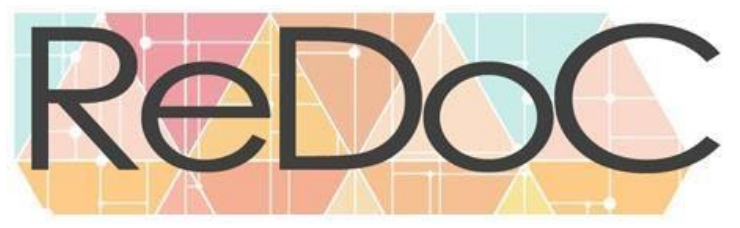

Revista Docência e Cibercultura

4.17- equipar as salas de recursos multifuncionais com mobiliários e materiais didático-pedagógicos adaptados para alunos com deficiência;

4.18- disponibilizar recursos de tecnologias assistivas (softwares, ponteira de cabeça, andador, órteses, próteses etc.) para os alunos com deficiências, TGD, TEA e altas habilidades/superdotação (BELÉM, 2015, p.45).

Tais estratégias precisam ser analisadas no contexto do atendimento do público da Educação Especial, na rede pública de ensino de Belém. Assim, cabe destacar que em relação a matrícula na rede municipal de ensino de Belém, os dados obtidos no Censo Escolar evidenciam que, por um lado, houve crescimento do número de ofertas de vagas em algumas etapas e modalidades de ensino da Educação Básica, como é o caso da Educação Infantil e Projovem e, por outro lado, ocorrera um declínio sucessivo a exemplo da EJA/Fundamental, conforme a tabela 1 a seguir:

Tabela 1. Número de Alunos Matriculados por Modalidade de Ensino e Ano na Rede Municipal de Belém, 2014 - 2018.

\begin{tabular}{lccccc}
\hline Modalidade de Ensino & \multicolumn{5}{c}{ Ano } \\
\hline Educação Infantil (Creche e Pré-escola) & 2014 & 2015 & 2016 & 2017 & 2018 \\
Ensino Fundamental & 18.530 & 18.891 & 19.909 & 20.694 & 20.314 \\
EJA Fundamental & 42.784 & 41.508 & 41.700 & 41.968 & 42.400 \\
Eja Médio & 7.209 & 6.610 & 6.563 & 6.654 & 6.231 \\
PROJOVEM & - & 46 & 36 & 39 & 54 \\
ENSINO MÉDIO & 1.701 & 2.265 & 2.271 & - & - \\
\hline Total & 146 & 122 & 132 & 155 & 124 \\
\hline
\end{tabular}

Fonte: Elaborada pelas autoras com base no Anuário Estatístico do Município de Belém, 2019.

A respeito da matrícula na Educação Especial, o Censo Escolar dos últimos anos aponta que a demanda por Atendimento Educacional Especializado vem crescendo na rede municipal de ensino de Belém, conforme demonstra a tabela 2 a seguir:

Tabela 2. Matrícula em Educação Especial na rede pública regular de ensino, no município de Belém, no período de 2015 a 2018. 


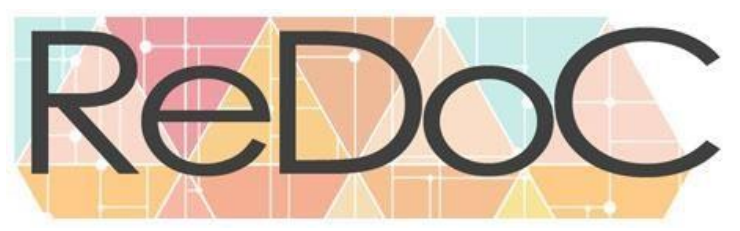

Revista Docência e Cibercultura

\begin{tabular}{lcccc}
\hline Modalidades & \multicolumn{3}{c}{ Anos } \\
& 2015 & 2016 & 2017 & 2018 \\
\hline Creche & 16 & 19 & 14 & 26 \\
Pré-Escola & 103 & 131 & 158 & 167 \\
Ensino Fundamental - anos iniciais & 789 & 819 & 1.017 & 1.100 \\
Ensino Fundamental - anos finais & 145 & 167 & 236 & 349 \\
\hline \multicolumn{1}{c}{ Total } & $\mathbf{1 . 0 5 3}$ & $\mathbf{1 . 1 3 6}$ & $\mathbf{1 . 4 2 5}$ & $\mathbf{1 . 6 4 2}$ \\
\hline Fonte: Elaborada pelas autoras, com base & & & & \\
\hline
\end{tabular}

Fonte: Elaborada pelas autoras, com base no Censo Escolar dos anos de 2015, 2016, 2017 e 2018 / Deed/Inep/MEC.

Os resultados sinalizam para um crescimento do número de matrículas de alunos públicoalvo da Educação Especial, na rede pública de ensino de Belém, no período analisado. Em 2015, a demanda era de 1.053, e em 2018, esse quantitativo saltou para 1.642. Estes dados revelam que existe uma demanda crescente por Atendimento Educacional Especializado (AEE) na rede municipal de ensino de Belém. A tabela 3, a seguir, indica o quantitativo de matrículas por tipo de deficiência no ano de 2016.

Tabela 3. Quantitativo por tipo de deficiência na rede pública municipal de ensino de Belém (2016)

\begin{tabular}{l|cccccccc|l}
\hline Ano & T.D & D.I & D.F & D.A & D.V & D.M & TEA & H.A & TOTAL \\
2016 & 37 & 538 & 113 & 97 & 73 & 79 & 318 & 04 & 1.259 \\
\hline
\end{tabular}

Fonte: Elaborada pelas autoras, com base na dissertação de Garcia (2018, p.34)

Percebe-se que a rede municipal de Belém tinha matriculados, no ano de 2016, 37 alunos com transtorno degenerativo; 538 com deficiência intelectual; 113 com deficiência física;

6 T. D= Transtorno degenerativo; D. I= Deficiência Intelectual; D. F= Deficiência Física; D. A= Deficiência Auditiva; D. V= Deficiência Visual; D.M= Deficiência Múltiplas; TEA= Transtorno do Espectro Autista; AH= Altas Habilidades.

\begin{tabular}{l|l|l|l|l|l|} 
(C) Redoc & Rio de Janeiro & v. 4 & n.1 & p. 71 & Jan/Abr 2020
\end{tabular}




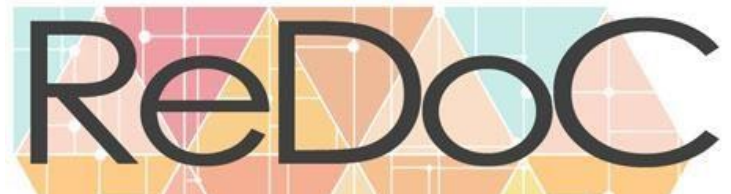

Revista Docência e Cibercultura

97 com deficiência auditiva; 73 com deficiência visual; 79 com deficiência múltipla; 318 com transtorno do espectro autista e quatro alunos com altas habilidades.

Quadro 2. Quantitativo de Sala de Recurso Multifuncional (SRM) das escolas municipais de BelémPA nos anos de 2014 a 2017.

\begin{tabular}{|c|c|}
\hline Ano & $\mathbf{N}^{\mathbf{0}}$ de SEM \\
\hline 2014 & 33 \\
\hline 2015 & 41 \\
\hline 2016 & 53 \\
\hline 2017 & 56 \\
\hline
\end{tabular}

Fonte: Elaborado pelas autoras, com base na dissertação de Garcia (2018, p.34) e no Plano Plurianual (PPA 2018-2021).

O Quadro 2 demostra o quantitativo de SRM das escolas municipais de Belém. Em 2014 a rede possuía 33 Salas de Recursos Multifuncionais. No ano de 2015 este número cresceu para 41 SRM. Em 2016 o crescimento foi de 13 salas nas escolas do município, passando a 53 unidades. Em 2017, passou para 56, com aumento de apenas três SRMs em relação ao ano anterior.

A Rede Municipal de Ensino de Belém (RME) é composta atualmente por 97 escolas; 51 Unidades Pedagógicas e 36 Unidades de Educação Infantil, totalizando 184 estabelecimentos de ensino municipais. Considerando que as Unidades Pedagógicas e Unidades de Educação Infantil não são contempladas com SRM, constata-se que até o ano de 2017 existem 56 unidades de salas de recursos na rede de Belém, isso indica que das 97 escolas, apenas $57 \%$ delas possuem salas de recursos. Com isso, percebe-se que apesar dos esforços empreendidos ao longo dessas duas décadas de educação na perspectiva inclusiva, ainda existem, na rede municipal de ensino de Belém, muitas escolas que não dispõem deste espaço. 


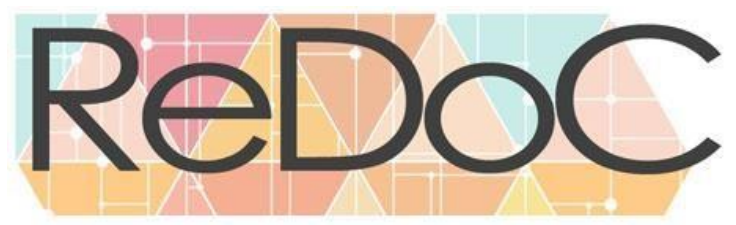

Revista Docência e Cibercultura

No Projeto de Lei de Diretrizes Orçamentárias (PLDO 2016), registra-se que a Secretaria Municipal de Educação de Belém (SEMEC), com o objetivo de garantir o acesso e a permanência dos alunos na Educação Básica e suas modalidades de ensino com qualidade, estabelece as seguintes metas:

Construir e ampliar as Salas de Recursos Multifuncionais em pelo menos $80 \%$ das Escolas da RME; Construir, adequar, ampliar salas de recursos multifuncionais em pelo menos $90 \%$ das Unidades Pedagógicas da RME; Manter 100\% das salas de recursos multifuncionais em condições de funcionamento; Garantir $100 \%$ de material de tecnologia assistiva e comunicação alternativa/aumentativa para os alunos com deficiência matriculados na RME (BELÉM, 2016, p.70, grifo das autoras).

Percebe-se que a SEMEC planeja ampliar o quantitativo de SRMs na rede municipal de ensino, com a criação de novas unidades, bem como equipar as já existentes com os recursos pedagógicos e Tecnologias Assistivas, deixando-as em condições de funcionamento. Para tanto, a rede elaborou dois instrumentos que objetivam fazer o levantamento das necessidades de acessibilidade das escolas - física e pedagógica - de forma a estruturar o planejamento das ações.

O primeiro documento que iremos apresentar tem como foco a acessibilidade dos espaços físicos e de mobiliários. O documento é enviado para escola indicar "sim" ou "não" em relação aos seguintes itens: carteira adaptada a sala de aula regular; banheiro acessível; rampas nas vias de acesso principais; portas alargadas; sinalização visual, tátil e sonora; bebedouro e outros mobiliários acessíveis (com espaço para especificação da quais são estes espaços).

O outro documento é especifico aos equipamentos das SRM, intitulado "Demanda de atualização dos itens de composição das Salas de Recursos Multifuncionais já implantadas”, e deve ser preenchido pelo professor da SRM. Este documento está vinculado ao planejamento do Plano de Ações Articuladas (PAR) 2016-2019, e está estruturado em quatro 


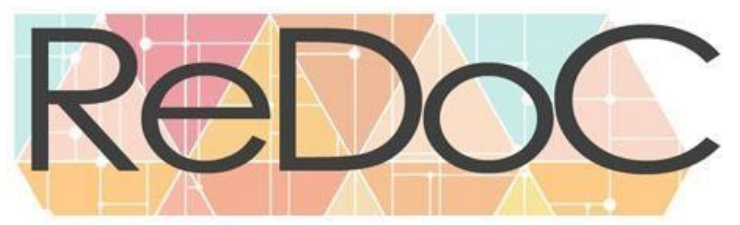

\section{Revista Docência e Cibercultura}

conjuntos de itens: kit de materiais didáticos e pedagógicos; equipamentos para Tecnologias Assistivas; equipamentos; mobiliário. Destaca-se que tal documento define a estrutura comum das SRMs no que se refere a composição das mesmas, conforme podemos observar no quadro a seguir:

Quadro 3. Inventário dos itens de composição das salas de recursos multifuncionais na rede de ensino de Belém

\begin{tabular}{|c|c|}
\hline Conjunto de Itens & Itens \\
\hline $\begin{array}{l}\text { Kits de materiais } \\
\text { didáticos pedagógicos }\end{array}$ & $\begin{array}{l}\text { Alfabeto móvel e sílabas; Material dourado; Caixa tátil; Dominó tátil; Memória } \\
\text { Tátil; Alfabeto Braille; Caixinha de números; Bolas com guizo; Bola de futebol } \\
\text { com guizo; Lupa eletrônica; Globo terrestre tátil; Calculadora sonora; Kit de } \\
\text { desenho geométrico; Regletes de mesa; Punções; Guias de Assinatura; Soroban. }\end{array}$ \\
\hline $\begin{array}{l}\text { Equipamentos para } \\
\text { Tecnologia Assistiva }\end{array}$ & $\begin{array}{l}\text { Scanner com voz; Máquina de escrever em braille; Mouse estático de esfera; } \\
\text { Teclado expandido com colmeia. }\end{array}$ \\
\hline Equipamentos & Computador; Estabilizador; Impressora multifuncional; Roteador wireless. \\
\hline Mobiliário & $\begin{array}{l}\text { Mesa de reunião; Cadeiras fixas; Cadeira giratória com braço; Mesa para } \\
\text { computador; Mesa para impressora; Armário. }\end{array}$ \\
\hline
\end{tabular}

Fonte: Elaborado pelas autoras, com base no documento "Demanda de atualização dos itens de composição das Salas de Recursos Multifuncionais já implantadas", vinculado ao planejamento do Plano de Ações Articuladas (PAR) 2016-2019.

O documento da rede está próximo ao que prevê o Programa Implantação de Salas de Recursos Multifuncionais, o qual define que devem ser disponibilizados para estudantes com deficiência os seguintes recursos de Tecnologia Assistiva: mouse com entrada para acionador; mouse estático de esfera; acionador de pressão; teclado expandido com colmeia; lupa eletrônica; notebook com diversas aplicações de acessibilidade; software para comunicação aumentativa e alternativa; esquema corporal; sacolão criativo; quebra-cabeças superpostos - sequência lógica; caixa com material dourado; tapete alfabético encaixado; dominó de associação de ideias; memória de numerais; alfabeto móvel e sílabas; caixa de números em tipo ampliado e em braille; kit de lupas manuais; alfabeto braille; dominó tátil; memória tátil de desenho geométrico; plano inclinado; bolas com guizo; scanner com voz; máquina de escrever em braille; globo terrestre tátil; calculadora sonora; kit de desenho 


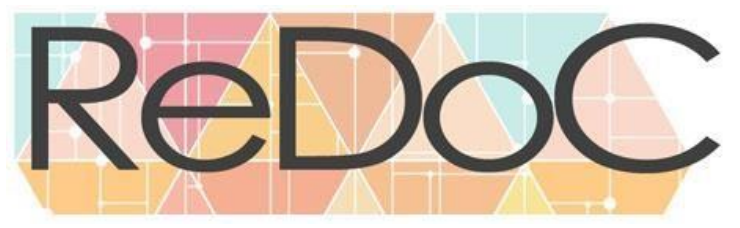

Revista Docência e Cibercultura

geométrico; regletes de mesa; punções; soroban; guias de assinatura; caixa de números em tipo ampliado e em braille (BRASIL, 2015b).

Contudo, destacamos que ainda que haja a preocupação do levantamento das demandas, a composição das salas - retiradas as possibilidades de confecção de materiais pelo professor - ainda apresenta uma configuração tímida.

Baseadas em Tonolli; Bersch (2017), ao classificarem os tipos de Tecnologias Assistivas e que recursos compõem cada tipo, identificamos uma multiplicidade de materiais que podem ser usados como forma de acessibilidade. Destes consideramos pertinente destacar:

$\checkmark$ Comunicação aumentativa e alternativa - Recursos, eletrônicos ou não, que permitem a comunicação expressiva e receptiva das pessoas sem a fala ou com limitações da mesma. São muito utilizadas as pranchas de comunicação com os símbolos PCS ou Bliss além de vocalizadores e softwares dedicados para este fim;

$\checkmark$ Recursos de acessibilidade ao computador - Equipamentos de entrada e saída (síntese de voz, Braille), auxílios alternativos de acesso (ponteiras de cabeça, de luz), teclados modificados ou alternativos, acionadores, softwares especiais (de reconhecimento de voz, etc.), que permitem as pessoas com deficiência a usarem o computador;

$\checkmark$ Órteses e próteses - Troca ou ajuste de partes do corpo, faltantes ou de funcionamento comprometido, por membros artificiais ou outros recursos ortopédicos (talas, apoios etc.). Incluem-se os protéticos para auxiliar nos déficits ou limitações cognitivas, como os gravadores de fita magnética ou digital que funcionam como lembretes instantâneos;

$\checkmark$ Auxílios para cegos ou com visão subnormal - Auxílios para grupos específicos que incluem lupas e lentes, Braille para equipamentos com síntese de voz, grandes telas de impressão, sistema de TV com aumento para leitura de documentos, publicações (TONOLLI; BERSCH, 2017, p.02).

Considerando a classificação dos autores acima, e espelhando a relação de materiais por eles listados aos materiais previstos pela SEMEC - Belém, observa-se que as tecnologias de acessibilidade ao computador e as de comunicação aumentativa e alternativa são modestas na rede, ainda que tenhamos um número significativo de alunos com deficiência visual e deficiência auditiva, os quais necessariamente poderiam se valer destas tecnologias como forma de favorecer a acessibilidade educacional. 


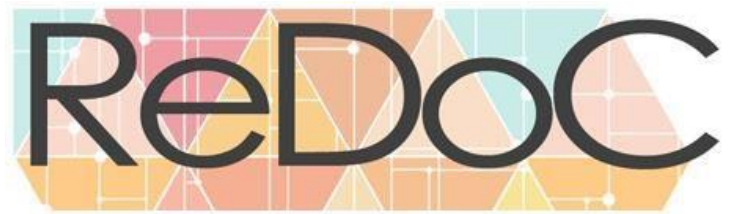

Revista Docência e Cibercultura

Cabe destacar também, na lista de itens que compõem o kit de materiais didáticos pedagógicos no documento "Demanda de atualização dos itens de composição das Salas de Recursos Multifuncionais já implantadas", que dos 17 itens, 13 se constituem recursos específicos para alunos com cegueira, ou com baixa visão. Diante deste dado, ficou evidente que a maioria dos recursos presentes nas SRMs são destinados ao atendimento desse público específico. No entanto, ressaltamos que a deficiência visual não representa a maior demanda de atendimento da rede. Conforme dados da tabela 3, as maiores demandas relacionam-se a deficiência intelectual, seguida de TEA, deficiência física, auditiva, mental.

A partir desse cenário, cabe indagar a respeito de como se encaminha a acessibilidade educacional, aos alunos com outros tipos de deficiência matriculados na rede de ensino de Belém, uma vez que as Tecnologias Assistivas disponíveis nas SRMs não contemplam as necessidades específicas desses alunos. Especialmente no caso de alunos com paralisia cerebral, ou outra deficiência que cause comprometimento motor mais severo, aos quais se impõe a necessidade do uso de recursos de Tecnologias Assistivas direcionadas para o atendimento educacional especializado destes alunos.

\section{CONSIDERAÇÕES FINAIS}

Diante dos dados analisados, conclui-se que a Secretaria Municipal de Educação de Belém tem empreendido ações que favorecem a Educação Especial na Perspectiva de Educação Inclusiva. Em relação à escolarização de pessoas com deficiência na rede regular de ensino, observou-se, a partir dos dados do Censo Escolar, que houve aumento progressivo do número de matrículas na rede municipal de ensino de Belém. Elemento indicador de que o direito de acesso à escolarização vem sendo garantido por meio da matrícula. Porém, ressaltamos que a inclusão escolar, como já destacado ao longo deste texto, não consiste apenas no ingresso do aluno na escola. A matrícula representa apenas o passo inicial desse 


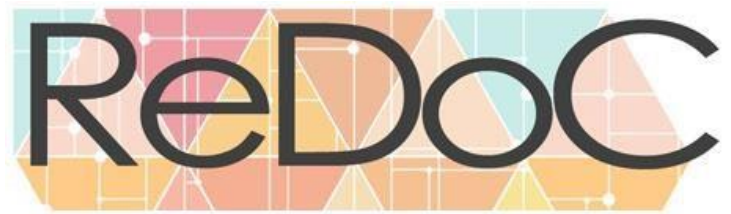

Revista Docência e Cibercultura

processo. É necessário oferecer condições de permanência. Tais condições revelam-se também necessárias no oferecimento dos serviços de apoio especializado.

Outro ponto importante a ser destacado, a partir da análise dos documentos levantados, refere-se à ampliação do quantitativo de Salas de Recursos Multifuncionais na rede municipal de ensino de Belém. Contudo, o aumento no número de unidades de SRMs ainda não contempla todas as escolas da rede. Tal fato demonstra a necessidade de investimentos públicos na infraestrutura destes espaços, assim como, também, a aquisição insumos que compõem as Salas de Recursos Multifuncionais, dentre os quais: de recursos pedagógicos e Tecnologias Assistivas.

Ainda que tenhamos identificado as ações para levantamento das demandas dos itens de composição das SRM da rede de ensino de Belém, identificamos uma configuração de sala modesta, no que se refere à disponibilização de recursos de Tecnologias Assistivas, o que pode imprimir ao professor uma necessidade maior de confecção de recursos que supram as necessidades dos alunos.

\section{REFERÊNCIAS}

ANTUNES, Celso. Inclusão: o nascer de uma nova pedagogia. São Paulo: Ciranda Cultural, 2008 .

BELÉM. Conselho Municipal da Educação. Resolução n. 012, de 23 de maio de 2007. Fixa diretrizes e normas educacionais e pedagógicas, para o atendimento dos educandos com necessidades especiais no Sistema Municipal de Ensino de Belém. Belém, PA, 2007. Disponível em: <http://cmebelem.com.br/wp-content/uploads/2015/09/Res12_07.pdf >. Acesso em: 27 jun. 2019.

BELÉM. Lei n. 9.129, de 24 de junho de 2015. Aprova o Plano Municipal de Educação de Belém e dá outras providências. Belém, PA, 2015. Disponível em: $<$ https://leismunicipais.com.br/a/pa/b/belem/lei-ordinaria/2015/912/9129/lei-ordinaria-n9129-2015-aprova-o-plano-municipal-de-educacao-pme-e-da-outras-providencias>, Acesso em: 27 jun. 2019. 


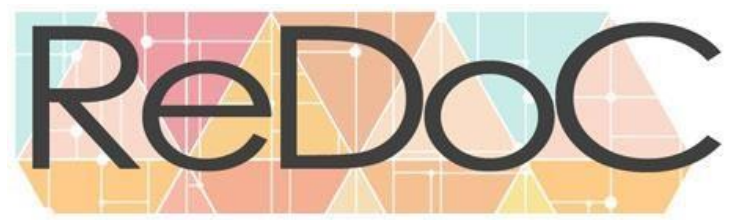

Revista Docência e Cibercultura

BELEM. Prefeitura Municipal de Belém. Projeto de lei de Diretrizes Orçamentárias (PLDO 2016-2018). Belém-PA, 2016.

BELEM. Prefeitura Municipal de Belém. Plano Plurianual (PPA 2018-2021), de julho de 2017. Belém-PA, 2017.

BELÉM. Prefeitura Municipal de Belém. Anuário Estatístico do município de Belém. 2019. Disponível em: < http://anuario.belem.pa.gov.br/index.php/tabela-educacao/>. Acesso em: 3 jan. 2020.

BERSCH, Rita de Cássia Reckziegel. Tecnologia Assistiva. In: SCHIRMER, Carolina Rizzotto et al. Atendimento educacional especializado- Deficiência Física. Brasília-DF, 2007, p.31-37. Disponível em:

<http://portal.mec.gov.br/seesp/arquivos/pdf/aee_df.pdf>. Acesso: 12 nov. 2019.

BERSCH, Rita de Cássia Reckziegel. Design de um serviço de tecnologia assistiva em escolas públicas. 2009. 231f. Dissertação (Mestrado em Design), Faculdade de Arquitetura, da Universidade Federal do Rio Grande do Sul, Porto Alegre, 2009.

BEYER, Hugo Otto. Da integração escolar à educação inclusiva: implicações pedagógicas. In: BAPTISTA, Cláudio Roberto (Org.) Inclusão e escolarização: multiplas perspectivas. Porto Alegre: Mediação, 2009. p.73-81.

BRASIL. Lei de Diretrizes e Bases da Educação Nacional. Lei $\mathrm{n}^{\circ}$ 9.394, 20 de dezembro de 1996. Disponível em: <http://www.planalto.gov.br/ccivil_03/leis/19394.htm>. Acesso: 7 jun. 2019.

BRASIL. Resolução CNE/CEB $n^{\circ}$ 02, de 11 de setembro de 2001. Diretrizes Nacionais para a Educação Especial na Educação Básica. Disponível em: <http://www.planalto.gov.br/ccivil_03/leis/19394.htm>. Acesso em: 5 out. 2019.

BRASIL. Ata VII - Comitê de Ajudas Técnicas - CAT. Secretaria Especial dos Direitos Humanos da Presidência da República (CORDE/SEDH/PR). 2007. Disponível em: <http://www.comunicacaoalternativa.com.br/artigos-cientificos $>$. Acesso em: 7 out. 2019.

BRASIL. Portaria Normativa $n^{o} 13$, de 24 de abril de 2007. Dispõe sobre a criação do Programa de Implantação de Salas de Recursos Multifuncionais. Brasília, 2007. Disponível em:

<http://portal.mec.gov.br/index.php?option=com_docman\&view=download\&alias=9935portaria-13-24-abril-2007\&Itemid=30192>. Acesso em: 2 ago. 2019. 


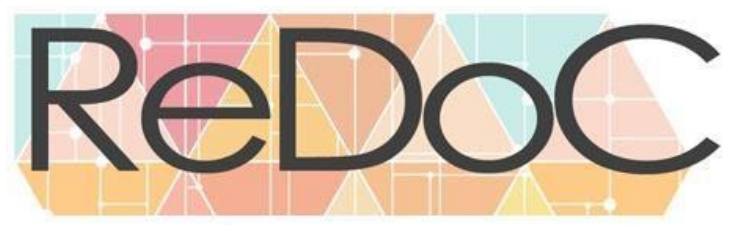

\section{Revista Docência e Cibercultura}

BRASIL. Ministério da Educação. Secretaria de Educação Especial. Política Nacional de Educação Especial na Perspectiva da Educação Inclusiva. Brasília, 2008. Disponível em: $\langle$ http://portal.mec.gov.br/arquivos/pdf/politicaeducespecial.pdf $>$. Acesso em: 2 ago. 2019.

BRASIL. Decreto $n^{o}$ 6.571, de 17 de setembro de 2008. Dispõe sobre o atendimento educacional especializado, regulamenta o parágrafo único do art. 60 da Lei no 9.394, de 20 de dezembro de 1996, e acrescenta dispositivo ao Decreto no 6.253, de 13 de novembro de 2007. Disponível em: <http://www.planalto.gov.br/ccivil_03/_Ato20072010/2008/Decreto/D6571.htm>. Acesso em: 11 ago. 2019.

BRASIL. Resolução CNE/CEB $n^{\circ}$ 04, de 02 de outubro de 2009. Diretrizes Operacionais para o Atendimento Educacional Especializado na Educação Básica. Diário Oficial da União. $\quad$ Brasília, 2009. Disponível em: http://portal.mec.gov.br/dmdocuments/rceb004_09.pdf. Acesso em: 10 out. 2019.

BRASIL, Decreto $n^{\circ} 7.611$, de 17 de novembro de 2011. Dispõe sobre a educação especial, o atendimento educacional especializado e dá outras providências. Disponível em: <http://www.planalto.gov.br/ccivil_03/_ato2011-2014/2011/decreto/d7611.htm>. Acesso em: 10 out. 2019.

BRASIL. Lei n. 13.146, de 6 de julho de 2015. Lei Brasileira de Inclusão da Pessoa com Deficiência. Diário Oficial da União. Brasília, 2015a. Disponível em:< http://www.planalto.gov.br/ccivil_03/_ato2015-2018/2015/lei/113146.htm>. Acesso em: 2 ago. 2019.

BRASIL. Ministério da Educação. Orientações para implementação da política de educação especial na perspectiva da educação inclusiva. Brasília, 2015b. Disponível em: $<$ http://portal.mec.gov.br/index.php?option=com_docman\&view=download\&alias=17237secadi-documento-subsidiario-2015\&category_slug=marco-2015-pdf\&Itemid=30192>.

Acesso em: 8 jan. 2020.

CORRÊA, Nesdete Mesquita; RODRIGUES, Ana Paula Neves. Tecnologia assistiva no Atendimento Educacional Especializado (AEE) de estudantes com deficiência. Revista Linhas. Florianópolis, v. 17, n. 35, p. 87-101, set./dez. 2016. Disponível em: < http://www.revistas.udesc.br/index.php/linhas/article/view/1984723817352016087>.

Acesso em: 5 jan. 2019.

FACHINETTI, Tamiris Aparecida; CARNEIRO, Relma Urel Carbone. A Tecnologia Assistiva como facilitadora no processo de inclusão: das políticas públicas a literatura. Revista de Política e Gestão Educacional. Araraquara, v.21, n. esp.3, p. 1588-1597, dez., 2017. Disponível em: <https://periodicos.fclar.unesp.br/rpge/article/view/10093/7162>. Acesso em: 26 jul. 2019. 


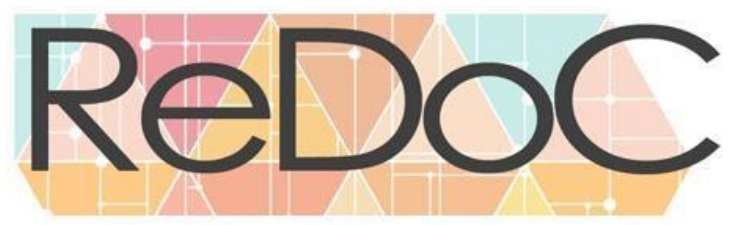

Revista Docência e Cibercultura

FERREIRA, Diana Lemes. Políticas de formação docente do projeto Escola Cabana: dilemas e desafios da implementação do programa de formação continuada. 2005. 197f. Dissertação (Mestrado em Educação), Universidade Federal do Pará, Belém, 2005.

GALVÃO FILHO, Teófilo Alves. Tecnologia Assistiva para uma Escola Inclusiva: Apropriação, Demandas e Perspectivas. 2009. 346f. Tese (Doutorado em Educação), Faculdade de Educação da Universidade Federal da Bahia, Salvador, 2009.

GALVÃO FILHO, Teófilo Alves; MIRANDA, Theresinha Guimarães. Tecnologia Assistiva e paradigmas educacionais: percepção e prática dos professores. In: REUNIÃO ANUAL DA ANPED, 2011, Natal, Anais da $34^{a}$ Reunião Anual da ANPEd, Natal, ANPED, 2011. Disponível em: < http://www.galvaofilho.net/Artigo_34_ANPEd.pdf>. Acesso em: 26 jul. 2019.

GARCIA, Daniele Cristina Salgado. O currículo da sala de recurso multifuncional: suas contribuições para processo de escolarização de alunos com deficiência do Ciclo I da EMEIEF Rotary-Belém-Pa. 2018. 183f. Dissertação (Mestrado em Educação), Universidade Federal do Pará, Belém, 2018.

GARCIA, Jesus Carlos Delgado et al. Pesquisa nacional de inovação em tecnologia assistiva III (PNITA III): principais resultados, análise e recomendações para as políticas públicas. São Paulo: ITS BRASIL, 2017.

GLAT, Rosana; BLANCO, Leila de Macedo Varela. Educação especial no contexto de uma educação inclusiva. In: GLAT, Rosana (Org.). Educação Inclusiva: cultura e cotidiano escolar. Rio de Janeiro: 7letras, 2007. p.15-35.

LÍBERA, Bianca Della; SILVA, Vanessa França da. Tecnologias digitais da informação e comunicação na educação de pessoas com deficiência visual. In: CARVALHO JÚNIOR, Arlindo Fernando Paiva de; LÍBERA, Bianca Della; GOMES, Márcia de Oliveira (Org.). Para além do olhar: políticas e práticas na educação de pessoas com deficiência visual. Curitiba: Appris, 2019. p.133-152.

QUIXABA, Maria Nilza Oliveira. A inclusão na educação: humanizar para educar melhor. São Paulo: Paulinas, 2015.

TONOLLI, José; BERSCH, Rita de Cássia Reckziegel. O que é Tecnologia Assistiva?. 2017. Disponível em: 〈http://www.assistiva.com.br/tassistiva.html >. Acesso em: 30 out. 2019. 